\title{
Influence of Attendance Policy Implementation on Faculty Absenteeism: Issues and Prospects for Policy Upgrade
}

\author{
Dassy Jane S. Maquilan, Ph.D. \\ College of Business Education, Technological Institute of the Philippines \\ 938 Aurora Boulevard, Cubao, Quezon City, Philippines \\ E-mail: djmaquilan.cbe@tip.edu.ph \\ Carl Mark B. Miniano, Ph.D., DBE (Corresponding author) \\ College of Administrative and Financial Sciences, AMA International \\ University-Bahrain
}

Building 829, Road 2013, Block 712, P.O. Box 8041, Salmabad, Kingdom of Bahrain

E-mail: cmminiano@amaiu.edu.bh

Received: May 20, 2019 Accepted: June 12, 2019 Online published: July 3, 2019

doi:10.5296/ijhrs.v9i3.15026 URL: https://doi.org/10.5296/ijhrs.v9i3.15026

\begin{abstract}
The study investigated if faculty absenteeism is influenced by the extent of policy implementation on attendance monitoring, reporting, and usage of records. Through the use of Focus Group Discussion, it also determined the issues and prospects surrounding the policy and its implementation, in an attempt to generate inputs for upgrading the attendance policies and procedures in a technological university operating in Quezon City and Manila City in the Philippines. Respondents of the study were comprised of faculty members, attendance checkers, academic heads, and Human Resource Department staff of the said institution. The results revealed that faculty absenteeism is not influenced by the extent of implementing the policy on attendance monitoring, reporting and usage of record. The study also discovered some policy issues such as uncommitted attendance checkers, improper and inconsistent attendance remarks, lenient implementation of the attendance monitoring policy, and lack of coordination among concerned departments.
\end{abstract}

Keywords: faculty absenteeism, attendance monitoring, attendance reporting, policy 
implementation, Philippines

\section{Introduction}

A sound policy is said to be the cornerstone of a successful management control system. While having a policy is undoubtedly just one side of the equation, examining the issues that surround these policies has proven useful in generating valuable insights on upgrading the human resource policies, and pinpointing the crtical issues that should be addressed in its implementation. Looking into the issues and concerns and the various modes of faculty attendance monitoring (Ami-Narh, Aziale, \& Akanferi, 2014; Deane \& Murphy, 2016) and exploring the currently existing modes of attendance monitoring (El-Abed, Giot, Hemery, \& Rosenberger, 2012; Hameed, Saquib, Ul-Hasan, \& Junejo, 2015; Lodha, Gupta, \& Jain, 2015) will greatly help in identifying factors to be considered in policy upgrades.

A plethora of researches conducted underscored that attendance has significant effects on student achievement (Joseph, Waymack, \& Zielaski, 2014) (Roby, 2013) (Tingle et al., 2012) (Miller, Murnane, \& Willet, 2007) (Sezgin, Koşar, Kılınç, \& Öğdem, 2014) (Iqbal, Muhammad, \& Haider, 2015). Prior to the student achievement however, the schools should ensure that the teachers are in the classroom to perform their responsibilities. Monitoring and verification of whether the faculty member is attending his or her class is a crucial part of the process. This activity is not easy when the system is using paper and pen to monitor the attendance of the academic staff, and is being conducted manually, since there is a possibility that the process will be circumvented or abused. (Glewwe, Kremer, Moulin, \& Zitzewitz, 2004). An effective control system should be done by the institution due to the issues on productivity and cost (Ehrenberg, Ehrenberg, Rees, \& Ehrenberg, 1991; Hermann \& Rockoff, 2012; Woods \& Montagno, 1997). On the faculty member's side, instances of being unduly marked late, under time, or absent persist. Monitoring could signify distrust but employers argue that through it they are able to protect the organization from unnecessary ill-effects. (Moussa, 2015) and in management parlance, to establish a control environment that will deter teacher absenteeism (McKenzie, Nugroho, Ozolins, McMilan, \& Sumarto, 2014).

\section{Literature Review}

\subsection{Attendance Monitoring Modalities}

It is a common practice for companies to have policies on employee attendance monitoring. In the context of educational institutions, this can mean attendance of teachers, or students. Ami-Narh et al., (2014) were able to clearly differentiate between computer-based and biometric-based attendance management systems. They further conclude; "biometric timekeeping technologies are more secured than traditional timekeeping methods." Another study states, "the use of biometric timekeeping technologies has better effect on organization labour cost as these are not susceptible to frequent breakdown as compared to traditional methods" Deane \& Murphy (2016). On the contrary, another research found out that using the traditional paper-based log-book to record attendance in a classroom-based learning activities was acceptable and more practical for students and staff. The said practice was also seen as to have facilitated better record keeping. This goes to say that regardless of whether it is done in 
a big organization or just a small classroom, the end goal of attendance monitoring is to have a transparent record keeping, embodying the company's existing policies. A group of authors also emphasized that monitoring when done by Program Heads, Head Teachers and the like, could be a cheaper alternative, not to mention the extra value that it could provide through establishing and maintaining a more personalized approach to monitoring. In this way, sets of information gathered through personal observations potential inputs could generate data that could be used by the government for planning purposes. This practice however could possibly lead to collusion among the program heads and the teachers, especially when financial rewards are attached (Cillers, Kasirye, Leaver, Serneels, \& Zeitlin, 2016). Another interesting way of monitoring attendance was employed by the NGO Seva Mandir in India (Duflo, E. Hanna \& Ryan, 2012) where the organization issued photo cameras to the teachers. The mechanics of the program was for one of the students to the take the picture of the whole class at the start and toward the end of the school day.

\subsection{Strategies in Improving Faculty Attendance}

The most prevalent strategies used in improving teacher attendance is the use of reward and punishment. In a study conducted in New York district, Jacobson (1989) investigated the effects of providing pay incentives on teacher absenteeism. The study revealed that in the initial year of the project implementation, a significant decline in teacher absences were noted. Consequently, a rose from 8 percent to 34 percent in perfect attendance was recorded, while a dramatic decline in teacher absences were noted. In India, a study was conducted to determine whether providing financial incentives can reduce the rate of teacher absenteeism. The study found out that an immediate and long lasting reduction in teacher absenteeism emerged as the effect of providing financial incentives for perfect attendance. (Duflo, E. Hanna \& Ryan, 2012). Another research however argues that monetary incentive does not result to a positive outcome on teacher attendance (Glewwe et al., 2004). Recognizing that one reason for teacher absenteeism is the demotivating effect of the poor student attendance, one interesting strategy proposed was the use of the concept called the "Share Goods" (Banerjee, King, \& Orazem, Peter F. Paterno, 2012). The strategy focused on improving student attendance to improve the attendance of teachers. In her District Administration Magazine article titled Attendance Incentive, Jackson shared the strategies used by Muhlenberg South Middleschool in Greenville, Kentucky to decrease teacher absenteeism rate (Jackson, 2018). Some of the strategies are the following; (1) Organize staff pep rallies; (2) Eliminate black out dates; (3) Shift to paid time off rather than separating sick days and personal days; (4) Start a teacher book club; (5) Cover classes on teacher's birthday, (6) Organize team building activities on PD days; (7) Provide meals for perfect attendance; (8) Give principals regular absentee data; (9), Put up "shout out" boards where students, staff and parents can post compliments and, (10) Offer bonus planning periods.

\subsection{Issues/concerns in Monitoring Academic Staff Attendance}

"Teacher absences fell in response to increased accountability pressure suggests that one mechanism through which consequential accountability policies affect student achievement is through increased teacher effort" (Gerhenson, 2015). Monitoring attendance encompasses 
employees' productivity or students' performance (Deane \& Murphy, 2016) while the working environment where the learning takes place, and the factors relevant to that environment were seen by many researchers as the key factors to achieving quality teaching, and more importantly good turn out in teacher attendance (McKenzie et al., 2014). Along these arguments, another author emphasized that people exhibits a great avoidance behaviour for un-conducive work places. This he added would result to increased absenteeism. On the contrary he concluded, a good working environment, facilitates good working attitude and behaviour, including good attendance record. Monitoring also increased concerns about employee privacy (Bringer, Chabanne, Le Metayer, \& Lescuyer, 2017) . A balance must therefore be established between the gains associated with monitoring, and the possible negative effects of perceived invasion of employees' privacy rights. The use of recent technologies however, makes employees think, that as they are monitored, their privacy is being breached. This makes the adoption of the new technologies more complicated in a sense, thus the balancing act between the gains and perils of such utilization is further made difficult (V. John Ella, J.D. \& P.C., 2016). Consequently, Moussa refers to these emerging technologies in monitoring employees as Electronic Performance Monitoring (EPM) (Moussa, 2015). According to him, "EPM Electronic performance monitoring (EPM) refers to the practice of using computers and/or telecommunication technology to collect, analyse, and report information about employee performance."

Pawar, Priya, \& Thorve (2016) in their research "Attendance Monitoring System (AMS), which is based on Android Application and Global Position System (GPS)" which monitors the attendance of employees utilizing the Android Operating System highlighted its speed advantage over the Desktop-based Biometric System. They further claimed that the said system could easily generate reports regardless of location. On the other hand, another researcher coined the term "Trilateral Biometric Adoption Model" (Terblanche, 2012). He expounds, "the model furnishes the biometric access control fraternity with a practical implementation framework that is both scalable and pliable to the extent that its applicability transcends biometric modality constraints."

A group of researchers emphasized that using face recognition to track the attendance of people, can actually perform reliably even with the different facial expressions, including the various lighting conditions and the physical pose of the person. (Nagothu \& Anitha, 2016; Swetha, Ashwini, \& Neshwasalih, 2015). Deane \& Murphy (2016) however found in their study that using paper-based attendance recording was acceptable and practical. However, some researchers remarked that paper-based attendance monitoring system is cumbersome whether it is used to monitor students, teachers, staff, or employees' attendance. This approach of however according to some authors, is time consuming and needs an automated and reliable system (Pawar et al., 2016). Ami-Narh and coleagues contend that it is a daunting task for employers in the Ghanaian business community (Ami-Narh et al., 2014). Even the attendance taking per se is in itself sometimes inaccurate, time consuming and laborious (Lodha et al., 2015). In an attempt at improving the conduct of monitoring faculty attendance, several researchers have focused on this area. Some researchers developed their own system to monitor teachers and staff' attendance through Biometrics and Radio 
Frequency Identification and link it to Android application modules (MB \& Roy, 2015).

The research findings of (Ami-Narh et al., 2014) underscored that; "biometric timekeeping technologies are more secured than traditional timekeeping methods," They further argued that, " it's use has better effects on organization labour cost as compared with traditional methods, and, biometric hardware technologies are not susceptible to frequent breakdown as compared to traditional methods." This simple means that the use of these methods and hard-wares are applicable in any organizational set-up.

Nicolas, Manares, Oquendo, \& Radislao (2012) argues, "for the non-teaching personnel, biometrics is very useful and very acceptable on their part while for the teaching personnel it is slightly useful and slightly acceptable." According to them, "based on the interviews conducted, it had a negative effect on the part of the teaching personnel so there is rejection on the use of it." The authors further noted that, "Biometrics technology counters teacher effectiveness since the teaching job cannot be quantified." They further opined that, "the teacher goes beyond his/her classroom activities and time frames should be flexible rather than restricted."

The thought of ease in conducting attendance monitoring while ensuring high level of security of the person have conspired to adopt biometric system technologies. "Biometrics can be defined as the measurable characteristics of individuals based on their physiological features or behavioural patterns that can be used to recognize or verify their identity." In technical terms, the authors continued, "biometrics is the automated technique of measuring a physical characteristic or personal trait of an individual and comparing that characteristic or trait to a database for purposes of recognizing that individual" (Emami, 2016; Krishnamurthi, Mary, B. N., \& Pereira, 2015)

\subsection{Theoretical Approaches to Policy Change and Implementation}

When a problem persists in the implementation of policy, or processes, either change or reform can address this situation. However, it is not easy to change. Change requires a rationale to define the multiple constraints involved in doing the change, trade-offs in selecting suitable solutions to the constraints, and theories and concepts to develop enhancements on the changes. For policy implementation, no 'one-size-fits-all' solutions exist in implementing the policy. The author says, "It is important to realize that there is diversity in implementation, and hence researchers should not look for one common theory." He further notes, that it is efficient and practical to formulate initial theories, which matches and combines the most convincing elements of different theories, and building those theories based on the context at hand.

Heads of Schools, with the threats of ever-changing institutional environment, manage these imperatives on a daily basis by facilitating a transformation the school's infrastructure. This is done through an administrative practice that is more aligned with policies and actual practice in the classroom. This approach of designing and redesigning activities aims to make the school's technical core less private and more transparent. The authors further added that rather than solely relying on political authority, head of schools could also utilize persuasion 
emphasizing to teachers the need to creatively to continually changing policy environment (Spillane \& Kenney, 2012). Developing policies in general, involve a systematic procedure of problem recognition, goals identification, alternatives generation to achieve desired results, evaluating the financial viability and the cost effectiveness of the generated alternatives, choosing the best alternative and formulating the plans and policies for the implementation of the chosen alternatives. Policy review and evaluation also generally passes through these stages (Jie, 2016).

Excellence and professionalism must be religiously observed in policy formulation, implementation, and review (Miniano, 2010). A Quality Assurance System generally necessitates a focus on two aspects, which include continuous improvement, and accountability. Once continuous improvement is established, accountability will be automatically developed (Teeroovengadum, Kamanabhan, \& Seebaluck, 2016).

\subsection{Attendance Monitoring Policy Prospects}

Another area that requires emphasis in managing teacher absenteeism is the review and evaluation of school procedures and policies (Knoster, 2016). Studies suggest modifying and strengthening these policies and procedures could result to significant improvements on teachers' attendance. Recommendations supported by researches include; "(1) more substantial, formative, and formal reporting of teacher absence data," " (2) requiring teachers to report absences directly to supervisors in face-to-face, in-person meetings," "(3) more consistent, proactive, and clear communication with staff concerning expectations for teacher attendance," "(4) the implementation of measures by district administration to hold school administration accountable for teacher absences," "(5) encouraging and promoting good health among teachers as a matter of policy," "(6) allowing teachers to carry over unused sick days as a means of eliminating a use it or lose it mentality," "(7) eliminating leave banks," and "(8) placing restrictions on the use of personal days to ensure that teachers are not using them at the expense of student learning (e.g., not using vacation leave time while school is in session)" (Knoster, 2016).

In the absence of control policies, teachers respond to changes. For example, "teachers who are required to report absences directly to their principal by telephone are absent less often than teachers who report their absences indirectly, to either a centralized reporting centre or a school-based message machine" (Miller et al., 2007). It is of great importance that policy-makers know that interventions implemented should last longer than a year, to really see the impact of the interventions made. The authors further argued that teachers tend to positively respond to interventions, when they are given sufficient time to observe the effects of the programs. This only means that a sufficient time should be set, for the program to progress in its normal course including the process of adoption of the people involved.

Duflo, E. Hanna \& Ryan (2012) assessed an activity in Rajasthan, India that checked educator truancy once a day utilizing cameras, and that made instructors' compensations a component of their participation by arbitrarily doling out schools to either this treatment or no treatment. The mediation diminished instructor non-attendance from 42 to 23 percent. Following a year, test scores in treatment schools were .17 of a standard deviation higher than 
in control schools, and grade fulfilment expanded results (Vegas, Ganimian, \& Jaimovich, 2012) while provision of monetary incentives can be effective to discourage absenteeism (Essaw \& John, 2013; Masino \& Nino-Zarazua, 2016; Vegas et al., 2012). Programs for educators should explore the importance of a "shared vision" of education in promoting positive climate to avert absenteeism (Cohen, McCabe, Michelli, \& Pickeral, 2009).

\section{Methodology}

This study used the descriptive method of research and utilized both quantitative and qualitative approaches. Survey questionnaires were administered to One Hundred Four respondents who were purposively selected using the following criteria: (1) Faculty members who had been teaching in the institution for more than two years; (2) Permanent full time attendance checkers who had been with the institution for more than two years; (3) Academic heads who had been in their position for more than two years; and (4) Human Resource Staff who had been with their position for more than two years.

Data gathered were analyzed using descriptive statistics. Weighted Mean and Standard Deviation were used to measure the extent of policy implementation, while the influence of policy implementation on faculty absenteeism was determined through Regression Analysis. Focus Group Discussion, and personal interview were conducted to determine the issues and prospects on the policies. The study was conducted in the two campuses of the university, one located in Quezon City, and the other one in the City of Manila, Philippines. Qualitative data were analyzed by drawing on patterns and themes from the responses of the participants.

\section{Results and Discussion}

\subsection{Influence of Policy Implementation on Faculty Absenteeism}

To determine if Faculty Absenteeism is influenced by the extent of policy implementation on attendance monitoring, reporting and usage of records, Multi Regression was conducted. Table 1 shows that in general, policy implementation has no significant influence on faculty absenteeism $(\mathrm{R}=0.24935, \mathrm{p}=0.14728)$.

Thus, hypothesis is supported. Consequently, faculty absenteeism is not significantly influenced by the extent of implementation of the Attendance Monitoring Policy $(\mathrm{R}=0.24935$, $\mathrm{p}=0.10473$ ). This simply means that regardless of whether the attendance is regularly and religiously checked based on schedule, the faculty members' manner and frequency of attending their respective classes will still be the same.

Extent of Attendance Reporting Policy implementation does not influence faculty absenteeism $(\mathrm{R}=0.24935, \mathrm{p}=0.24989)$, These connotes that regardless of whether daily report on their class attendance are timely received as a feedback by both the faculty members, and the academic administrators, faculty absenteeism appeared to be at the same rate. Finally Usage of Record Policy does not influence faculty absenteeism $(R=0.24935, p=0.21609)$. While the faculty members knew that absences will affect their salary, their course load and potentially jeopardize their chance of being promoted, still, it did not influence their rate of absenteeism. 
Table 1. Influence of Policy Implementation on Faculty Absenteeism

\begin{tabular}{|c|c|c|c|c|c|c|c|}
\hline \multicolumn{4}{|l|}{ Regression Statistics } & & & & \\
\hline \multicolumn{4}{|l|}{$R$} & \multicolumn{4}{|l|}{0.24935} \\
\hline \multicolumn{4}{|l|}{$R$-Squared } & \multicolumn{4}{|l|}{0.06217} \\
\hline \multicolumn{4}{|l|}{ Adjusted R-Squared } & \multicolumn{4}{|l|}{0.02828} \\
\hline \multicolumn{4}{|l|}{$N$} & \multicolumn{4}{|l|}{87} \\
\hline \multicolumn{8}{|l|}{ ANOVA } \\
\hline & \multicolumn{2}{|l|}{ d.f. } & $S S$ & $M S$ & \multicolumn{2}{|l|}{$F$} & $p$-value \\
\hline Regression & \multicolumn{2}{|l|}{3} & 32.18169 & 10.72723 & \multicolumn{2}{|l|}{1.83418} & 0.14728 \\
\hline Residual & 83 & & 5.42751 & 5.84852 & & & \\
\hline \multirow[t]{2}{*}{ Total } & 86 & & 517.60920 & & & & \\
\hline & Coefficient & $\begin{array}{l}\text { Standard } \\
\text { Error }\end{array}$ & $\mathrm{LCL}$ & UCL & t Stat & p-value & $\mathrm{H} 0(5 \%)$ \\
\hline Intercept & 2.35843 & 2.35810 & -2.33173 & 7.04860 & 1.00014 & 0.32015 & accepted \\
\hline AttendanceMonitoringPolicy & 0.59986 & 0.36570 & -0.12751 & 1.32723 & 1.64030 & 0.10473 & accepted \\
\hline AttendanceReportingPolicy & -0.47081 & 0.40632 & -1.27897 & 0.33735 & -1.15872 & 0.24989 & accepted \\
\hline RecordUsagePolicy & -0.43455 & 0.34862 & -1.12794 & 0.25884 & -1.24650 & 0.21609 & accepted \\
\hline
\end{tabular}

\subsection{Extent of Attendance Monitoring Policy Implementation}

Figure 1 shows the mean values of the respondents' perception on the extent the policy on attendance monitoring is being implemented.

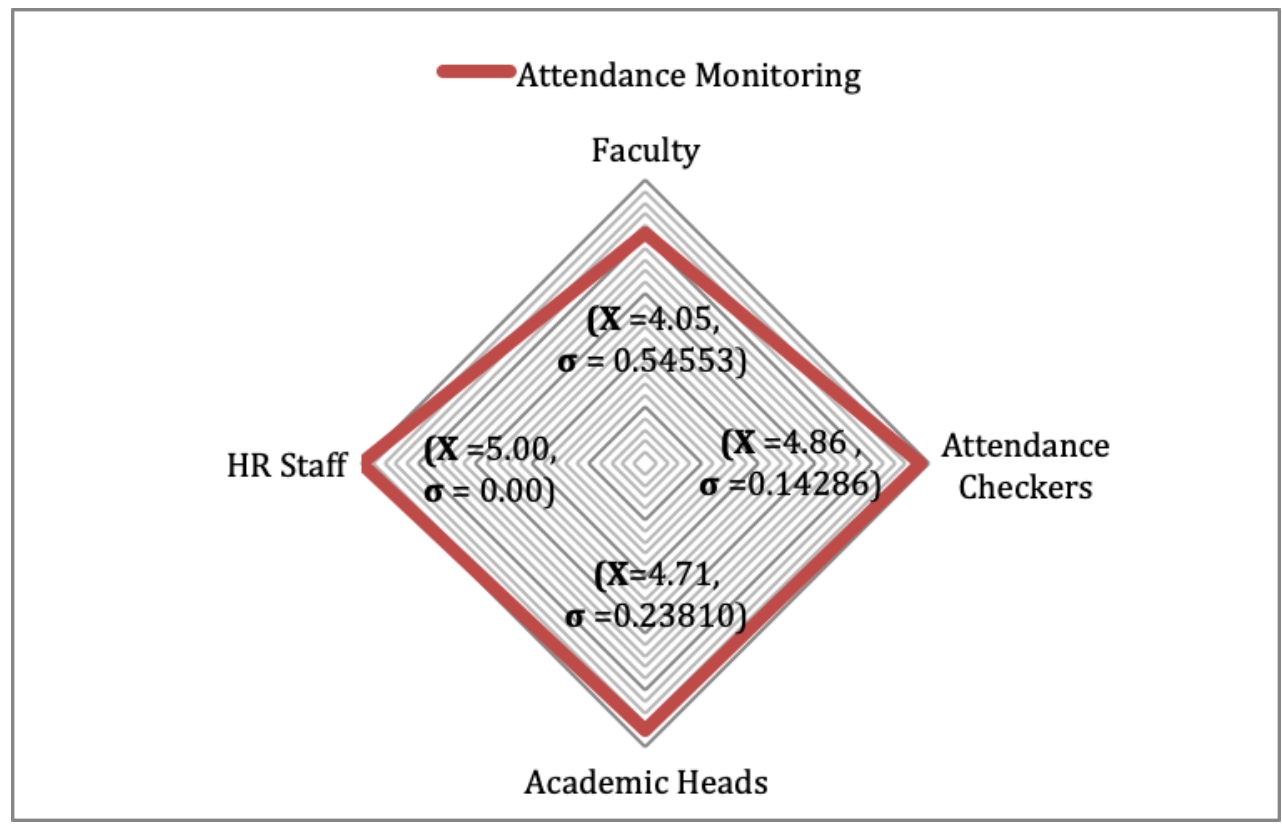

Figure 1. Comparative Perception on the Extent of Implementation of Attendance Monitoring Policy

It is interesting to note that the faculty members registered the lowest mean value $(\bar{X}=4.05, \sigma$ $=0.54553$ ), which could be interpreted that they consider the policy as being implemented at a "High" extent. On the other hand, the HR staff claimed that the policy is implemented at a "Very High" extent $(\overline{\mathrm{X}}=5.00, \sigma=0)$. These results indicate that the attendance checking policy is implemented at a "High" extent. 


\section{Macrothink}

International Journal of Human Resource Studies

ISSN 2162-3058 2019, Vol. 9, No. 3

Generally, the respondents consider the procedures "Checkers are assigned particular schedules", "Checking schedules are followed by the checkers"; and "First round made by the checkers considered the 15 minutes grace period" to be implemented at a "Very High" extent, while, the procedures such as "After 15 minutes all faculty members who are not in their respective classrooms are marked late"; and "A second round is made to check those faculty members noticed late in the first round to accurately record the number of minutes of being late" were only implemented at a "High" extent. It can be inferred from these findings that the HR has been very clear with the time schedule and classroom assignments that need to be checked by the checkers, but the latter had noticeably been a little soft in implementing the policy on tardiness.

\subsection{Extent of Attendance Reporting Policy Implementation}

Figure 2 illustrates the comparative perceptions of the respondents as regards the extent the Attendance Reporting Policy is being implemented in the institution.

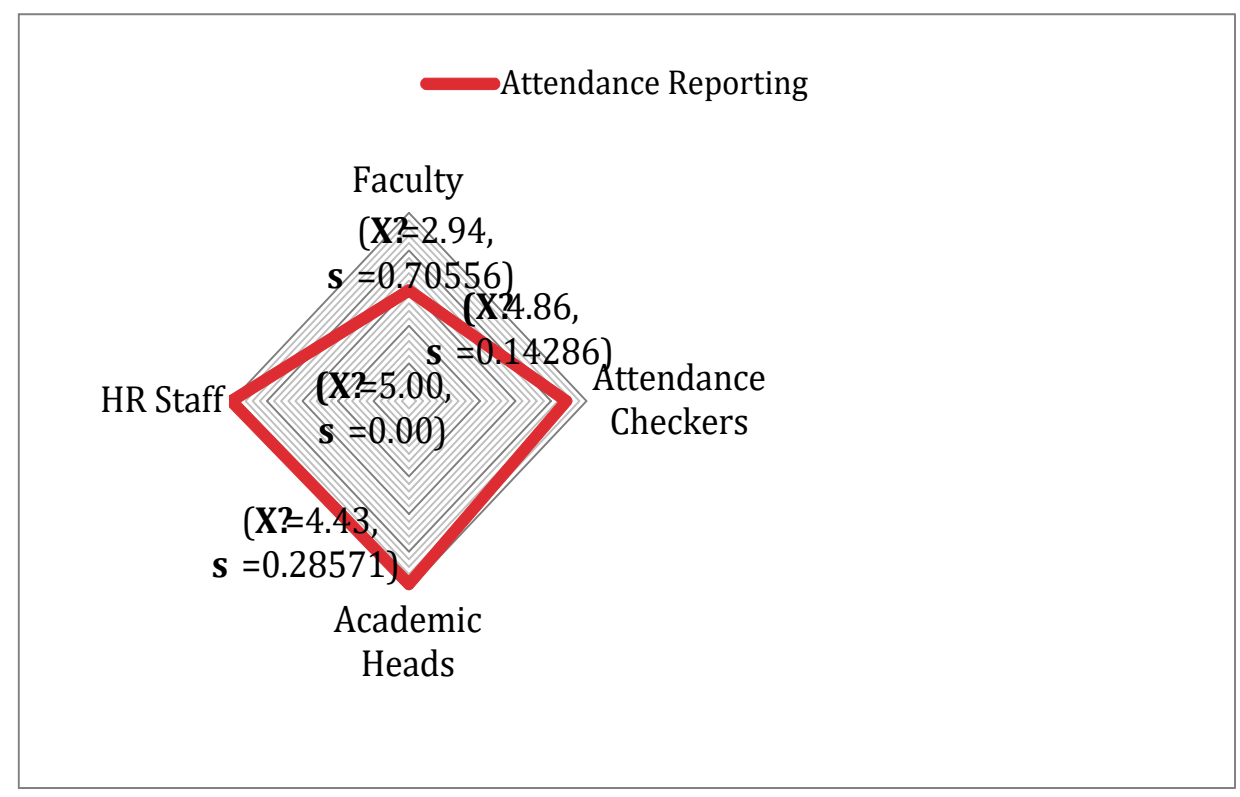

Figure 2. Comparative Perception on the Extent of Implementation of Attendance Reporting Policy

While the HR staff, and the Attendance Checkers have perceived that this policy is implemented at a "Very High" extent $(\overline{\mathrm{X}}=5.00, \sigma=0.00)$, and $(\overline{\mathrm{X}} 4.86, \sigma=0.14286)$, the faculty members however were obviously do not see it that way $(\bar{X}=2.94, \sigma=0.70556)$. The HR staff, and attendance checkers alike obviously expect no direct benefit from the attendance performance of the faculty members. This was however different in the case of the heads of department who have direct command responsibility with the teachers, and therefore will be indirectly affected by the situation $(\overline{\mathrm{X}}=4.43, \sigma=0.28571)$.

The result however generally indicates that the policy on attendance reporting is implemented at a "High" extent. In an organization where the system is in order, recognizing its functionality and capability is always warranted, and this was apparent with the actions of the 
attendance checkers. The ratings that led to a discrepancy in the responses revealed an opportunity for the institution to improve its policy in this area.

The perceived extent of implementation showed variability of the responses ranging from "Moderate" extent in the procedures "errors in reporting by the checkers are easily addressed and changed" to a "High" extent for the procedures "faculty members who are present are reported correctly", and "faculty members who are absent are reported with remarks indicating if he/she is excused, on leave or unofficial leave". The discrepancies were clarified through a follow-up interview, and the key informants claimed that not all faculty members who were absent were truly marked as absent. On the other hand, other key informants also admitted that there were cases were faculty members who were on official leave but were erroneously marked as absent. Other key informants gave some suggestions on how to manage this issue, stating that the Human Resource Department should have an earlier clearance for the faculty members who will have an official business outside the campus, like attending seminars or on official leave, and this must be posted as an online announcement in the Attendance Monitoring System, so that the checkers will be notified during attendance recording.

\subsection{Extent of Attendance Record Usage Policy Implementation}

Figure 3 shows the comparative responses as regards the extent of policy implementation on usage of attendance records. The HR Staff, attendance checker, and academic heads unanimously claimed that the said policy and procedures were implemented at a "Very High" extent $(\overline{\mathrm{X}}=4.8, \sigma=0.28571 ; \overline{\mathrm{X}} 4.7, \sigma=0.54813 ; \overline{\mathrm{X}}=4.8, \sigma=0.28571)$. The Faculty members however, claimed that the policy was only implemented at a "High" extent. Generally however, these results connote that "attendance reports made by the checkers are used as a basis for payroll computation.

On the other hand, the procedure "attendance reports made by the checkers form as basis for general disciplinary actions" garnered the lowest extent of implementation. Faculty members thought that although disciplinary action is desired to curb the breaking of rules and regulations stipulated in the General Disciplinary Sanctions (GDS) manual, they felt it was not applied fairly to all. Notwithstanding the fact that the penalty for chronic absenteeism is dismissal, one key-informant revealed that a chronic absentee faculty member was even awarded with a permanent employment status. This is absolutely an alarming case since it sends a message that the institution does not apply the policies equally and fairly among the faculty members. 


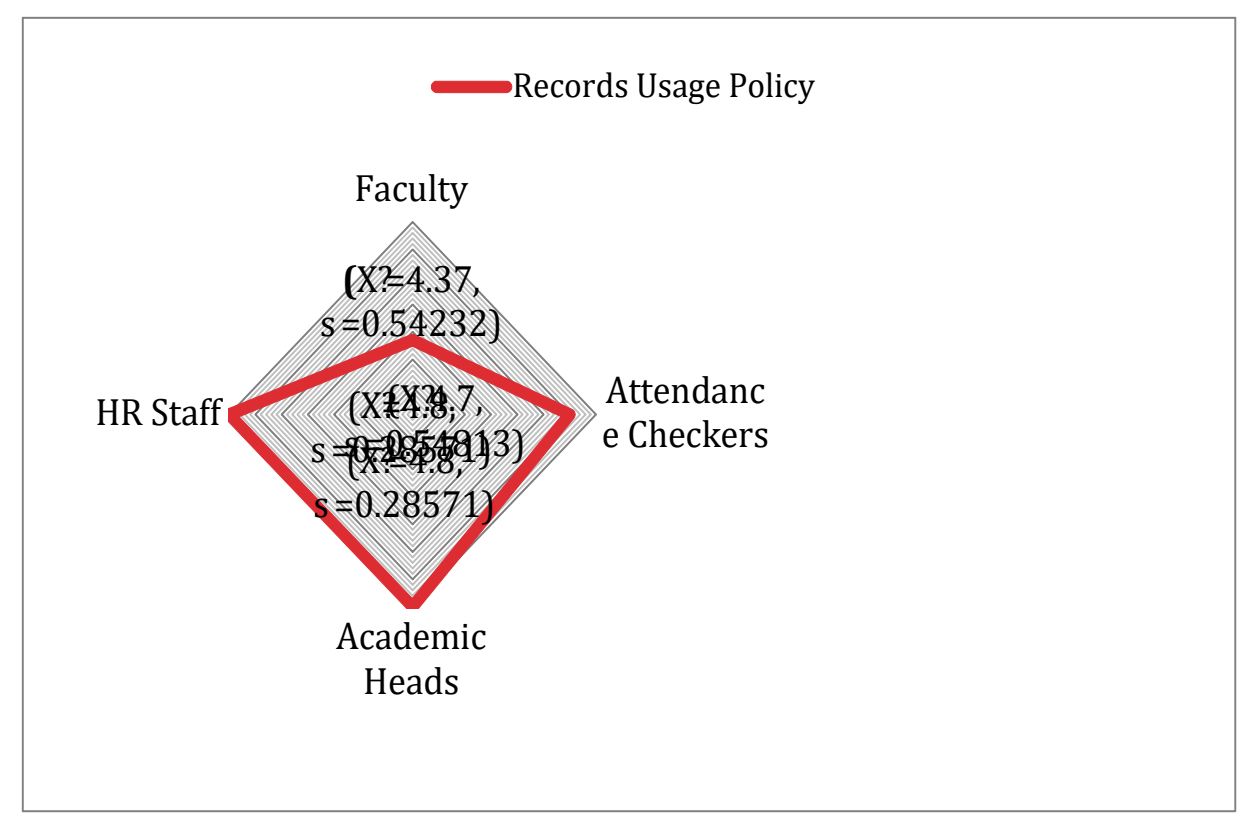

Figure 3. Comparative Perception on the Extent of Implementation of Records Usage Policy

It is also interesting to note, that the procedure "Attendance records are used by the program heads in providing teaching load assignments", while still interpreted as implemented to a "High" extent, got the lowest weighted mean. This goes to say that not all heads of departments are religiously using attendance record as a basis in determining and assigning course loads. On the contrary, it is deemed to a deterrent for a chronic absentee since a reduction in course load will have a longer impact in terms of salary. Implementing it to a high extent however if Attendance Monitoring is accurate, will be a strong signal to the faculty that the policy is seriously implemented

\subsection{Policy Issues and Prospects on Attendance Monitoring, Recording and Usage of Record}

Responses from the Focus Group Discussions and In-depth Interviews revealed prevalent themes on issues and prospects pertaining to the attendance monitoring policy. These include; attendance checkers with low work commitment, erroneous attendance remarks, lenient implementation of attendance monitoring policy, and lack of coordination among concerned academic departments.

\subsubsection{Low Work Commitment Among Attendance Checkers}

Different reasons surfaced for weak commitment. Uncommitted checkers can be a concern on multitasking performance particularly on the role of shifting ability Although checkers have definite assignment schedules, indicated that accomplishing many goals within a certain period of time by switching between individual tasks draw cognitive rigidity that could impair the performance of the employees (Szumowska \& Kossowska, 2016). From the key-informants' responses, it was found out that there are uncommitted checkers. While most of the checkers do their job religiously and efficiently, there were those who do otherwise. 
These checkers are obviously a liability to the organization, not to mention the potential morale problems they might result to the faculty members who were unduly marked absent.

\subsubsection{Erroneous Attendance Remarks}

While the attendance checkers provide the necessary remarks on the attendance of the faculty members as absent, late, or under-time, incorrect remarks jeopardize the faculty members' performance evaluation and the compensation. From the key-informants' responses, it was found out that there are improper remarks in reporting the attendance of the faculty members. Inaccurate and inconsistent specification of remarks appeared as major concern of both the human resources personnel and the faculty members, which were also corroborated by the heads of department. One attendance checker however, admitted of confirming the attendance with the concerned faculty member before reporting it.

Whether the system is paperless (Chao, 2015) or using an online system (Rastogi \& Srivastava, 2017) whatever remarks provided by the checkers cannot give beneficial intervention when the checkers are reporting improperly. Hence, checkers must be extra careful in indicating the remarks in their attendance monitoring report.

\subsubsection{Leniency in Attendance Monitoring}

Leniency is a result of low motivation and multitasking (Skaugset et al., 2016). Some people could lose their enthusiasm in the myriads of tasks. Most of the study participants agreed that most of the attendance checkers were lenient in the implementation of attendance monitoring policy. While the latters' leniency could have generated positive results for the faculty members, these on the contrary has resulted to some reporting inconsistencies that eventually led to several complaints from the faculty members.

\subsubsection{Lack of Proper Coordination Among Concerned Departments}

Changes in information without being disseminated to those who will be affected create chaos in the system. The human resource personnel, and attendance checkers confirmed occurrences of complaints from the faculty members of absences credited to them when they were attending seminars, doing official business outside of the institution, or simply changing their class schedule or rooms. The problem happens when the faculty member failed to accomplish the official business form, change of rooms and schedules for that should be submitted to the Human Resources Department (HRD) and the Dean's office respectively, for proper documentation. Hence, the result is an uninformed checkers.

Whatever the system is, the faculty members who changed their class schedules and room, and will attend outside seminars prepare the required documents submitted to the HRD and the Dean's office for proper revision of the changes and logging of permission to leave the work area. The checkers cannot be held responsible or blamed (Leephaijaroen, 2016) for the shortcoming of the faculty members to document necessary information salient to their attendance standing.

\section{Conclusion}

The extent at which policies on attendance monitoring, reporting, and usage of attendance 
record are implemented in the subject university has no significant influence on faculty absenteeism. While the respondents claimed that policies have been implemented to a "High" to a "Very High" extent, they however, were able to identify some issues and prospects that could be properly addressed in the institution's policy review. Most crucial among those issues are the low work commitment among attendance checkers, leniency in attendance monitoring, and lack of proper coordination among concerned departments.

\section{References}

Ami-Narh, J. T., Aziale, L. K., \& Akanferi, A. (2014). The Adoption of Biometric Fingerprint Timekeeping Technology in the Ghanaian Business Community - Effectiveness and Impact. International Journal of Computer Applications, 85(9), 32-39. https://doi.org/10.5120/14871-3246

Banerjee, R., King, E. M., \& Orazem, P. F., \& Paterno, E. M. (2012). Student and Teacher Attendance: The Role of Shared Goods in Reducing Absenteeism. Economics of Education Review, 31(5), 563-574. https://doi.org/10.1016/j.econedurev.2012.04.002

Bringer, J., Chabanne, H., Le Metayer, D., \& Lescuyer, R. (2017). Biometric Systems Private by Design: Reasoning about privacy properties of biometric system architectures. Transactions on Data Privacy (Vol. 11).

Chao, C. (2015). Implementing A Paperleass System for Small and Medium-Sized Businesses $(S M B S)$. University of Oregon.

Cillers, J., Kasirye, I., Leaver, C., Serneels, P. M., \& Zeitlin, A. (2016). Pay for Locally Monitored Performance? A Welfare Analysis for Teacher Attendance in Ugandan Primary Schools.

Cohen, J., McCabe, E. M., Michelli, N. M., \& Pickeral, T. (2009). School Climate: Research, Policy, Practice and, Teacher Education, 111(1), 180-213.

Deane, R., \& Murphy, D. (2016). Student and staff experiences of attendance Monitoring in undergraduate obstetrics and gynecology: A cross sectional study. Advances in Medical Education and Practice, 7, 233-240. https://doi.org/10.2147/AMEP.S99447

Duflo, E. Hanna, R., \& Ryan, S. P. (2012). Incentives Work: Getting Teachers to Come to School. American Economic Review, 102(14), 1241-1278. https://doi.org/10.1257/aer.102.4.1241

Ehrenberg, R. G., Ehrenberg, R. A., Rees, D. I., \& Ehrenberg, E. L. (1991). School District Leave Policies, Teacher Absenteeism, and Student Achievement. Journal of Human Resources, 26(1), 72-105. https://doi.org/10.2307/145717

El-Abed, M., Giot, R., Hemery, B., \& Rosenberger, C. (2012). Evaluation of biometric systems: a study of user's acceptance and satisfaction. Computers and Security, 20(6-7), 427-445.

Emami, C. (2016). Trends \& issues, (511), 1-5. 
Essaw, D. W., \& John, I. (2013). The Effectiveness of Human Resource Management Policies on Teachers: A Case Study of Ghana Education Service in Tamale Metropolis, Ghana. Educational Research, 4(2), 153-162.

Gerhenson, S. (2015). Performance Standards and Employee Effort: Evidence From Teacher Absences. Journal of Policy Analysis and Management, 35(3), 615-638. https://doi.org/10.1002/pam.21910

Glewwe, P., Kremer, M., Moulin, S., \& Zitzewitz, E. (2004). Retrospective vs. prospective analyses of school inputs: the case of flipcharts in Kenya. Journal of Development Economics, 74(1), 251-258. https://doi.org/10.1016/j.jdeveco.2003.12.010

Hameed, S., Saquib, S. M. T., Ul-Hasan, M., \& Junejo, F. (2015). Radio Frequency Identification (RFID) Based Attendance and Asseement System with Wireless Dtabased Records. Procedia- Social and Behavioral Sciences, 195, 2889-2895. https://doi.org/10.1016/j.sbspro.2015.06.414

Hermann, M. A., \& Rockoff, J. E. (2012). Worker Absence and Productivity: Evidence from Teaching. Journal of Labor Economics, 30(4), 749-782. https://doi.org/10.1086/666537

Iqbal, N., Muhammad, S., \& Haider, N. (2015). To Explore the Causes of Absenteeism at Government and Private Primary Schools: A Case Study from Pakistan. International Letters of Social and Humanistic Sciences (Vol. 54). https://doi.org/10.18052/www.scipress.com/ILSHS.54.21

Jackson, N. M. (2018). K12 educator attendance incentive.

Jacobson, S. (1989). The Effects of Pay Incentives on Teacher Absenteeism. The Journal of Human Resources, 24(2), 280-286. https://doi.org/10.2307/145856

Jie, N. D. (2016). TOWARDS A FRAMEWORK OF EDUCATION POLICY ANALYSIS THF Literature Review. THF Literature Review. Retrieved from http://www.headfoundation.org/papers/2016_-_5)_Towards_a_Framework_of_Education_Pol icy_Analysis_.pdf

Joseph, N., Waymack, N., \& Zielaski, D. (2014). Roll Call: The importance of teacher attendance. National Council for Teacher Quality. Retrieved from http://www.nctq.org/dmsStage/RollCall_TeacherAttendance

Knoster, K. C. (2016). Strategies for Addressing Student and Teacher Absenteeism: A Literature Review. North Central Comprehensive Center. Retrieved from http://search.ebscohost.com/login.aspx?direct=true $\& d b=$ eric $\& A N=E D 584860 \&$ site=ehost-liv $\mathrm{e}$

Krishnamurthi, K., Mary, S. I., B. N., S., \& Pereira, A. (2015). Fingerprint Based Attendance System. International Journal of Advanced Research in Computer and Communications Engineering, 4(3), 621-623. https://doi.org/10.17148/ijarcce.2015.43149

Leephaijaroen, S. (2016). Effects of Big 5 Personality Traits and Organizational 
Commitments on Organizational Citizenship Behavior of Support Staff at Ubon Ratchathani Rjabat University, Thailand. Kasetsart Journal of Social Sciences, 37, 104-111. https://doi.org/10.1016/j.kjss.2015.03.002

Lodha, R., Gupta, S., \& Jain, H. N. (2015). Bluetooth Smart Based Attendance Management $\begin{array}{llll}\text { System. Procedia } \quad \text { Computer } & \text { Science, 45, }\end{array}$ https://doi.org/10.1016/j.procs.2015.03.094

Masino, S., \& Nino-Zarazua, M. (2016). What works to improve the quality of student learning in developing countries? International Journal of Educational Development, 43, 53-65. https://doi.org/10.1016/j.ijedudev.2015.11.012

MB, S., \& Roy, R. (2015). A web enabled secured system for attendance monitoring and real time location tracking using Biometric and Radio Frequency Identification (RFID) technology. https://doi.org/10.1109/ICCCI.2015.7218103

McKenzie, P., Nugroho, D., Ozolins, C., McMilan, J., \& Sumarto, S. (2014). Study on Teacher Absenteeism in Indonesia 2014.

Miller, R. T., Murnane, R. J., \& Willet, J. B. (2007). Do Teachers Absences Impact Student Achievement? Longitudinal Evidence from One Urban School District. NBER Working Paper No. 13356. https://doi.org/10.3386/w13356

Miniano, C. M. B. (2010). Industry-based Business Values in Selected Higher Education Institutions (HEIs) : Inputs to Values-based Institutional Relations Program Enhancement. The University Belt Consortium Research Journal, 3(4), 47-63.

Moussa, M. (2015). Monitoring Employee Behavior Through the Use of Technology and Issues of Employee Privacy in America. SAGE Open, 5(2), 1-13. https://doi.org/10.1177/2158244015580168

Nagothu, S. K., \& Anitha, G. (2016). GPS Aided Autonomous Monitoring and Attendance System. Procedia Computer Science, 87, 99-104. https://doi.org/10.1016/j.procs.2016.05.133

Nicolas, W. J., Manares, L. R., Oquendo, M. L., \& Radislao, A. F. A. (2012). Perception and Acceptance on the Usefulness of Fingerprint Biometric Technology Among Non-teaching and Teaching Personnel of Aklan State University: Basis for Policy Reccommendation.

Pawar, S., Priya, K., \& Thorve, U. (2016). Android Application for Attendance Monitoring System using Biometric Overview and Survey. International Journal on Recent Innovation Trends in Computing and Communication, 4(1), 26-29.

Rastogi, A., \& Srivastava, G. (2017). E-HRM: Emerging HR Practices in Private Banks. International Journal of Engineering and Management Research, 7(3), 111-116.

Roby, D. (2013). Teacher Attendance Effects on Student Achievement: Research Study of Ohio Schools. Education, 134(2), 201-206. https://doi.org/10.1111/hea.12008_38

Sezgin, F., Koşar, S., Kılınç, A., \& Öğdem, Z. (2014). Teacher Absenteeism in Turkish Primary Schools: A Qualitative Perspective from School Principals. International Online 
Journal of Educational Sciences (Vol. 6). https://doi.org/10.15345/iojes.2014.03.010

Skaugset, L. M., Farrell, S., Carney, M., Wolff, M., Santen, S. A., Perry, M., \& Cico, S. J. (2016). Can You Multitask? Evidence and Limitations of Task Switching and Multitasking in Emergency Medicine. Annals of Emergency Medicine, 68(2), 189-195. https://doi.org/10.1016/j.annemergmed.2015.10.003

Spillane, J. P., \& Kenney, A. W. (2012). School Administration in a Changing Education Sector: The U.S. Experience. Journal Of Educational Administration, 50(5), 541-561. https://doi.org/10.1108/09578231211249817

Swetha, K. S., Ashwini, A., \& Neshwasalih, C. (2015). Survey on Attendance Management System Using Face Recognition. International Journal of Innovative Research in Computer and Communication Engineering, 3(11), 10455-10457.

Szumowska, E., \& Kossowska, M. (2016). Need for Closure and Multi-tasking Performance: The Role of Shifting Ability. Personality and Individual Differences, 96, 12-17. https://doi.org/10.1016/j.paid.2016.02.055

Teeroovengadum, V., Kamanabhan, T. J., \& Seebaluck, A. K. (2016). Measuring Service Quality in Higher Education: Dvelopment of a Hierarchical Model (HESQUAL). Quality Assurance in Education, 24(2), 244-258. https://doi.org/10.1108/QAE-06-2014-0028

Terblanche, L. (2012). Breaking the barriers of resistance towards adoption and infusion of biometric solutions. Biometric Technology Today, $\quad 8, \quad 5-9$. https://doi.org/10.1016/S0969-4765(12)70167-4

Tingle, L. R., Schoeneberger, J., Schools, C., Wang, C., Algozzine, B., \& Kerr, E. (2012). An Analysis of Teacher Absence and Student Achievement. Education, 133(2), 367-382.

John, E. V., \& Jackson, L. P. C. (2016). EMPLOYEE MONITORING AND WORKPLACE PRIVACY LAW AMERICAN BAR ASSOCIATION Section of Labor and Employment Law National Symposium on Technology in Labor \&amp; Employment Law. Retrieved from https://www.americanbar.org/content/dam/aba/events/labor_law/2016/04/tech/papers/monitor ing_ella.authcheckdam.pdf

Vegas, E., Ganimian, A., \& Jaimovich, A. (2012). Learning From the Best: Improving Learning Through Effective Teacher Policies. Washington D.C.

Woods, R. C., \& Montagno, R. V. (1997). Determining the Negative Effect of Teacher Attendance on Student Performance. Education, 118(2), 307-316.

\section{Copyright Disclaimer}

Copyright for this article is retained by the author(s), with first publication rights granted to the journal.

This is an open-access article distributed under the terms and conditions of the Creative Commons Attribution license (http://creativecommons.org/licenses/by/4.0/). 